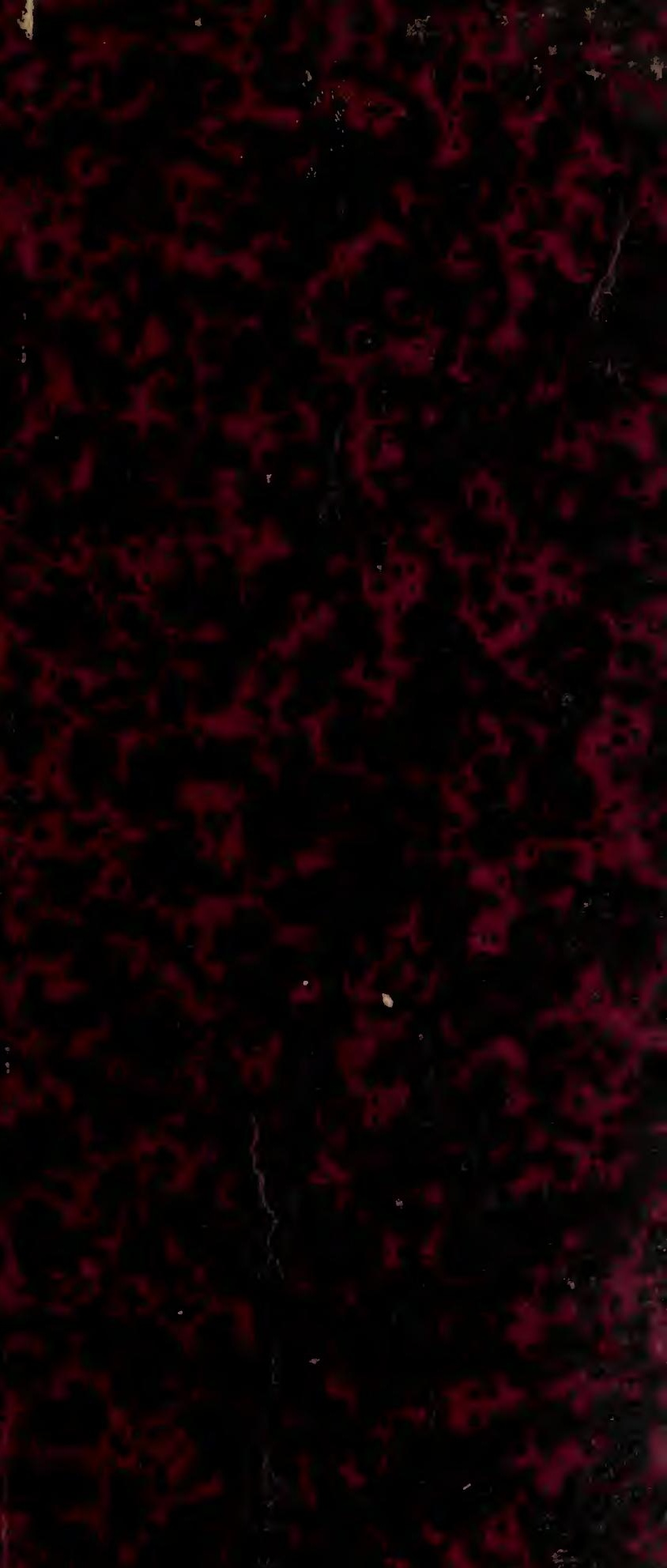




\section{Ma-G}

\section{HARVARD UNIVERSITY.}

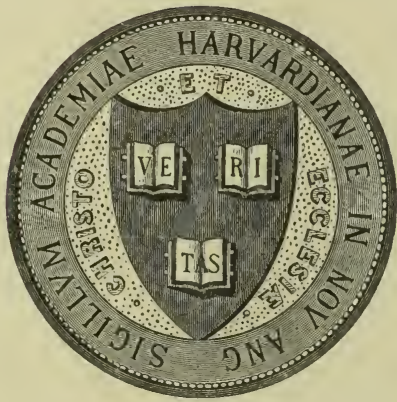

\section{I B R A R Y}

OF THE

MUSEUM OF COMPARATIVE ZOÖLOGY.

28,878

GIFT OF

ALEX. AGASSIZ.

Sovember 4,1898

Eentered March 12, 1907. 



\title{
Ueber die Wildschafe.
}

Von

\author{
Dr. A. Girtanner, St. Gallen.
}

Separatabdruck aus dem Jahresbericht der St. Gallischen Naturwissenschaftlichen Gesellschaft 1896/97.

Wenn unter Säugetierforschern das Kapitel der Wildschafe zur Sprache kommt, so finden wir in neuerer Zeit einerseits ein besonders reges Interesse an dieser Tiergruppe vor, anderseits aber auch die Überzeugung ausgesprochen, dass wir uns über dieselbe gegenwärtig nach mancher Richtung noch im Unklaren befinden. Dies gilt sowohl hinsichtlich ihrer Abgrenzung gegen die nächstverwandten Ziegen, Antilopen und Rinder, und bezüglich der Trennung der Arten innerhalb der Gruppe der Wildschafe selbst, als auch für die Anzahl der die Erde bewohnenden Species und die Naturgeschichte der bisher bekannt gewordenen, namentlich der asiatischen.

Wir dürfen uns indessen hierüber bei der zum Teil heute noch sehr geringen Zugänglichkeit ihrer enorm ausgedehnten Wohngebiete nicht wundern, wenn wir bedenken, dass unsere Kenntnisse noch weniger gross sind bezüglich des der Forschung scheinbar doch weit zugänglichern Hausschafes nach dessen örtlicher Herkunft, der artlichen Abstammung, der verschiedenen Rassen etc.

Jene Fragen über die Wildschafe werden voraussichtlich sogar schon lange beantwortet sein, wenn wir mit 
denen über das Hausschaf vielleicht erst um weniges, vielleicht selbst gar nicht rortärts gekommen sind. Gelehrte Hypothesen und Theorien sind eben keine Lösungen wissenschaftlicher Fragen, umsoweniger sogar, wie mir scheint, je mehr ihrer über eine und dieselbe Materie aufgestellt werden. - So der Forscher.

Wenn in Jägerkreisen jener weiten Jagdgebiete der Erde. welche keine Wildschafarten, sondern nur die einen oder andern Hausschafrassen beherbergen, von Wildschafen als von edlem, begehrenswertem Jagdwilde gesprochen wird. so begegnet man. im Gegensatze zu den Forschern, gewöhnlich einem geringschätzigen Achselzucken und Lächeln. Doch darum keine Feindschaft nicht: denn ror jenen schwebt ja nur das Bild eines aus mauerdicker Borniertheit und schätzbarer Strumpfwolle, aus grenzenlosem Terstandesmangel und lieblich duftendem Braten. aus der bemitleidenswertesten Hülflosigkeit, einem schrecklichen Geplärr, zwei blöden Glotzaugen, ebenso vielen Hangohren und einer wahren Schlachtbank-Jammergestalt zusammengesetzten, gleich nützlichen wie servilen Kulturgeschöpfes - des Hausschafes.

Wieder anders denkt der Jäger in den Wohnstätten irgend einer ron allen Wildschafarten, deren Scheuheit und Torsicht, aber auch Findigkeit und Beweglichkeit, rerbunden mit einer Sprung- und Kletterfähigkeit, die denjenigen ron Steinbock und Gemse nicht nachstehen, ihm wohlbekannte Dinge sind. Tor seinem Auge steht, im Rahmen der erhabenen Hochgebirgsscenerie, das Bild eines geistig sehr selbständigen Wesens ron imposanter Erscheinung und Gestalt. Er liebt die Jagd auf Wildschafe auch deshalb leidenschaftlich, weil er sie als eine an Aufregung reiche, seine intellektuellen und physischen 
Kräfte vollauf in Anspruch nehmende, aber auch alle Strapazen vollauf lohnende kennt:

Als Schafe (Oves) bezeichnen wir bekanntlich die $\mathrm{Zu}-$ gehörigen einer Unterfamilie der Horntiere, die ihrerseits wieder zu den Wiederkäuern zählen. Unter diesen, wie speciell unter den Horntieren, stellen sie sich zu den mittelgrossen Formen. Die typischen Schafe besitzen ausnahmslos Tränengruben (also auch Tränendrüsen) und Klauendrüsen. Der Schädel zeigt eine konkave Stirn, aber konvexe Nasenbeine. Auf dem Schädel sitzen, aus demselben selbst herauswachsend, die zwei knöchernen Stirnoder Hornzapfen, umgeben von den quergerunzelten, harten Hornschalen oder Hornscheiden. Von diesen Hornschalen ist bei den einen Schafarten die linke rechts, die rechte links im Raume gewunden, bei den andern aber die linke links, die rechte rechts. Infolge dessen weichen bei den erstern die Hornspitzen auseinander, während sie dagegen bei den letztern nach hinten zu stehen kommen, wodurch sie sich dem Ziegengehörn nähern. $\mathrm{Zu}$ den typischen Schafen gruppieren sich die erstern, auch abgesehen von der genannten Gehörnspecialität. - Alle Wildschafarten sind hochbeinig, von kräftiger, eher schlanker als plumper Gestalt. Als Gebirgstiere sind sie mit harten, kräftigen Hufen und selbst im Sommerkleid mit dichter, doppelter Behaarung versehen. Unter seinen Grannen wächst im Herbst ein Unterwollkleid, das sich im Frühjahr ablöst, durch die Bewegungen des Tieres (schütteln, scheuern, gehen) zwischen den Grannen hindurch sich emporarbeitet und schliesslich in grossen Fetzen und Flocken abfällt. Hingegen finden wir bei keiner Wildschafart das starke dauernde Wollkleid, das Vliess des Hausschafes, welches diesem erst die Kultur im Laufe der Jahrtausende angezüchtet und 
angeerbt hat. - Intellektuell stehen die Wildschafe ebenso hoch, wie die Hausschafe tief, zum Unterschiede von der Hausziege, welche, obwohl wahrscheinlich schon ebenso lange wie das Schaf im Dienste der Kultur und des Menschen stehend, ihr Wildziegennaturell, ihre geistige Selbständigkeit und die vorteilhafte äussere Erscheinung bei weitem nicht in demselben Grade dahingegeben hat. Es ist indessen nicht zu übersehen, dass im Gebirge gehaltene und deshalb mehr oder weniger sich selbst überlassene Schafe - von Haus aus Gebirgstiere - sowohl intellektuell als in der äussern Erscheinung vorteilhaft von ihren Tiefland und Stall bewohnenden Artgenossen sich unterscheiden, wie dies jeder Alpenwanderer zu beobachten Gelegenheit findet.

Wildschafe leben, so weit bis jetzt bekannt, nur auf den Gebirgsketten der nördlichen Erdhälfte; in Asien ungefähr von der Südgrenze der Polarländer bis annähernd zur Nordgrenze der heissen Zone, dort aber nur in bedeutender Meereshöhe; in Afrika bloss im Norden; in Europa einzig im Süden des Erdteils. - - Die riesenhafte Ländermasse Asiens, überaus reich an hochorganisierten Tierformen der verschiedensten Familien, beherbergt auch weitaus am meisten Wiederkäuer, die meisten der zu denselben gehörenden Horntiere und unter ihnen beinahe alle Wildschafarten.

Dass, im Gegensatze zu Asien, der äusserst artenarmen australischen Fauna sämtliche Paarzeher, also auch die Wildschafe fehlen, ist angesichts der Trockenheit dieser ausserdem heissen Tieflandsgebiete leicht erklärlich. Der Mensch hat zwar dort Wiederkäuer und andere domestizierte Paarzeher mit Erfolg eingeführt; aber nur unter seinem Schutz und mit Hülfe seiner Urbarisierungs-Be- 
strebungen gedeihen jene enormen Schaf- und Rinderherden. Und doch reicht dieser Schutz nicht weit genug, um zeitweise durch Wassermangel herbeigeführten Vegetationsmangel und durch diesen verursachte riesenhafte Verluste an jenen Herden zu verhindern.

Auffallend ist, dass der grosse nordamerikanische Kontinent, der doch in seinen Hochgebirgen alle zur Erhaltung von Wildschaf- und Wildziegen-Arten nötigen Bedingungen erfüllen zu können scheint, zur Zeit keine ächte Wildziege und nur eine Wildschafart - das mächtige Dickhornschaf (Ovis montana) - besitzt. - Kein Wildschaf beherbergen Süd- und Centralamerika.

So viel wir bis jetzt wissen, bewohnt nur ein Wildschaf Afrika und zwar nur einen Teil seines Nordens - das schon stark an die Ziegen sich anlehnende Mähnenschaf (Ovis tragelaphus s. Ammotragus tragelaphus). - Europa hat einzig im Süden, auf der Insel Sardinien eine Wildschafart aufzuweisen, den uns am besten bekannten Muflon (Ovis Musimon), während die ganze Alpenkette gegenwärtig keine besitzt und vielleicht auch nie eine solche besessen hat. In Böhmen sind zwar, wie Prof. Th. Studer meldet, im Diluvium Reste kleiner Schafe gefunden worden, die nach der Beschaffenheit (resp. Struktur) der Knochen als von wild lebenden herrührend bezeichnet werden müssen, ferner hat derselbe Forscher im Schweizerbild bei Schaffhausen ebensolche in der gelben (paläolithischen) Schicht nachweisen können. Die Funde seien aber so spärliche, dass sich absolut keine Schlüsse auf Gestalt und Art dieser Schafe ziehen lassen. Ueberdies falle ihr Vorkommen in eine so unendlich weit zurückliegende Zeit, in welcher die Zusammensetzung der Fauna eine von jener der Pfahlbauperiode so grundverschiedene war, dass sich kein $\mathrm{Zu}$ - 
sammenhang finden lasse. Hingegen haben die Funde in den schweizerischen Pfahlbauten, vom Stein bis zur Bronze, die schon damalige Existenz wenigstens dreier HausschafRassen ergeben, die jedoch unter sich wieder gewaltig differieren und durchaus nicht aufeinander zurückgeführt werden können. Dass keine derselben in wildem Zustande lebte, wird als sicher angenommen; wenigstens deutet die Porosität der Knochen auf Haustiere. Das Schaf muss schon so lange Zeit mit dem Menschen gewandert sein, dass wir darüber den Faden verloren zu haben scheinen, der uns zu seiner Herkunft zurückführen könnte. Deshalb ist auch die Frage über den Ursprung des Hausschafes eine der schwierigsten und wird dies immer mehr, da der Fund neuer Rassen in prähistorischen Ablagerungen die Sache ungemein kompliziert. - Im weitern kennen wir wohl das Torfschaf als Mitbewohner der Pfahlbauten. Wie mir scheint, ist jedoch noch nicht sicher festgestellt, ob es einmal als wild lebende Art vorhanden gewesen, oder ob es als bereits domestiziertes Tier dem Pfahlbauer unseres Landes zugeführt wurde, oder aber ob dieser es selbst aus einem Wildtier herausgezüchtet hat. Als ebenso unsicher muss es, alles in allem genommen, bezeichnet werden, ob die jetzt existierenden Hausschafrassen in den Gegenden früherer Pfahlbauten ganz, teilweise oder gar nicht aus dem domestizierten Torfschaf hervorgegangen sind. Nach den Angaben von Fachmännern sollen zwar in den Gebirgen Graubündens zur Zeit da und dort noch Hausschafe getroffen werden, welche grosse Ähnlichkeit mit dem kleinen, hochbeinigen, gracilgebauten Torfschafe haben; doch konnte ich selbst solche nicht finden. Wohl aber gibt es in den Walliser-Alpen nicht selten noch Ziegenböcke, die den Steinbock-Hausziegen-Blendlingen der ein- 
gegangenen Steinbockbastard-Kolonie im Welschtobel bei Arosa sowohl in der Gehörnbildung wie im ganzen Exterieur aufs Haar gleichen; dieselben scheinen selbst jetzt noch mehr Steinbockblut mit sich zu führen, als es bei jenen Blendlingen aus der Mandria-Züchterei der Fall war, und ihre heutige Existenz ist wohl auf die frühere Mitbewohnung jener Alpen durch den Steinbock und seine grosse Neigung zur Vermischung mit der Hausziege, die bekanntlich meist fruchtbar ausfällt, zurückzuführen. Unter den letzten Generationen des Steinbocks in den Schweizeralpen dürfte diese Neigung aus nahe liegenden Gründen eine über das frühere, gewöhnliche Mass noch hinausgehende gewesen sein. Vielleicht war es dasselbe beim Torfschaf, das jetzt noch in entfernten lebenden Anklängen an seine frühere Existenz erinnert. Doch sind selbstredend die Zeiträume zwischen dem Verschwinden des Torfschafes und dem Aussterben des Alpensteinbockes bei uns so verschieden lange, dass sich hieraus wohl kaum begründete bezügliche Schlüsse ziehen lassen.

Wie eingangs bemerkt, steht heute die Gruppe der Wildschafe nicht als ein festgegründetes, gegen andere Tiergruppen wohl abgegrenztes Ganzes da. Vielmehr trennt sie sich ziemlich schwer ab sowohl von den Rindern, wie von den Ziegen und den Antilopen. Am leichtesten erscheint die Trennung von den Rindern durch die Übergangsformen des Moschusochsen und des Gemsbüffels, die aber beide wohl mehr zu den Rindern als zu den Schafen zu zählen sind. Indien besitzt einige antilopenartige Horntiere, die den Schafen in mancher Hinsicht nahe stehen. Am meisten Zusammenhang haben die Schafe mit den Ziegen (und Steinbockarten), wie denn bekanntlich beide von manchen Forschern systematisch überhaupt nicht ge- 
trennt werden. Den Hirschen stehen die Schafe bedeutend ferner, schon allein durch die bei beiden Gruppen grundverschiedene Entstehung und weitere Lebensentwicklung des Geweihes und des Gehörns.

Wenn wir nun zu einer kurzen Besprechung einiger uns in verschiedener Hinsicht zunächst interessierenden Wildschafarten übergehen, so wird es sich empfehlen, dieselben zuerst als solche $z u$ behandeln und einige weitere Erörterungen erst am Schlusse anzubringen, da sich dieselben dann leichter verständlich gestalten dürften. Das "Illustrierte Tierleben" Brehms habe ich bei dieser Abhandlung gänzlich bei Seite gelassen, weil es sich wohl in den Händen der meisten sich um Zoologie überhaupt Interessierenden befindet. Ich habe mich aber um so mehr beflissen, da, wo ich aus fremden Quellen schöpfen musste, nur neuen Originalberichten solcher Männer zu folgen, die mir als ebenso tüchtige Kenner wie Jäger dieser Wildschafe und ihrer Heimstätten bekannt sind. Wertvolle briefliche Notizen und litterarische Nachweise verdanke ich wärmstens meinen Freunden Prof. Dr. Th. Studer, Prof. Dr. C. Keller und Dr. Langkavel (Zeitschrift "Zool. Garten" a. d. O.); grössere Beiträge ausser meinem Freunde BaillieGrohman solchen in Tunesien und auf Sardinien, sowie Herrn W. Peter's Abhandlung über Ovis jubata Pet. Endlich sei noch dankend erwähnt, dass die Herren Museumsassistent Bächler und Präparator Ghidini die genaue Uebersetzung der italienischen Originalabhandlung besorgt haben.

\section{Mïhnenschaf.}

(Ovis tragelaphus s. Ammotragus tragelaphus.)

Ich wähle als erste Art dieses die Gebirgsketten Nordafrika's bewohnende Wildschaf, weil es uns am besten von 
den Ziegen zu den Schafen hinüberführt. Es besitzt nämlich wohl die Klauendrüsen der letztern, dagegen fehlen ihm, wie den Ziegen, die Tränengruben, wie es überhaupt nicht bloss im ganzen Exterieur, sondern auch im Bane der Hufe oder Klauen noch mehr ziegen- als schafartiges zeigt. Es ist, entsprechend den tellurischen und klimatischen Verhältnissen der hochgelegenen Felsenwildnis seiner Heimat, ein sehr kräftig gebautes, resistenzfähig ausgestattetes Tier. Der Schädel ist im Stirnteil, wie bei allen ein schweres Gehörn tragenden Arten, der breiten, starken Stirn- oder Hornzapfen wegen breit angelegt, nach vorn sehr in die Länge gezogen, schmal in der Nasengegend und in der Schnauzenpartie. Das Stirnbein ist flach, die sehr wenig gewölbten Nasenbeine verlaufen vorne getrennt, von der Ramsnase der ächten Schafe zeigt sich noch kaum eine Andeutung. Das Gehörn des alten Widders hat ebenfalls mit dem der ächten Wildschafe wenig Ähnlichkeit; an der Wurzel steht es nahe beisammen, biegt sich zuerst etwas nach vorne, dann in flachem Bogen stark nach aussen und hinten, mit den Spitzen leicht ein- und abwärts. Im Vergleich zu den typischen Wildschafen weist es nur schwache Querrunzelung auf, hingegen besitzt es noch die ziegenartige Leiste und den vordern Wurzelsporn, allerdings in abgeschwächtem Grade. Ebenfalls abweichend trägt auch das erwachsene weibliche Tier ein stattliches, in seiner Gestalt dem des männlichen ähnliches Gehörn. Bei allen ächten Wildschafen kommt dem Weibchen entweder kein, oder nur ein sehr kleiner, dem der weiblichen Wildziegen enstprechender Hörnerschmuck zu. Das weibliche Mähnenschaf besitzt ausnahmsweise ausserdem sogar die scheinbare Manneszierde: die Kehl- und Beinmähne, wenn auch etwas schwächer als der Widder. Dieser hat 
einen kurzen Hals mit äusserst kräftig entwickelter Hals-, namentlich Nackenmuskulatur, wie alle Tiere mit grossen oder schweren Gehörnen. Jene und die sehr stark angelegte Halswirbelsäule ermöglichen es ihnen ja allein, mit in den Nacken zurückgeworfenem und dennoch nicht wankendem Kopf ohne Gefährde durch die Felsen dahinzustürmen, Felsmauern gedankenschnell zu erklimmen. ohne das Gleichgewicht zu verlieren. sich hoch über solche herunter zu stürzen und ihre wütenden Hornkämpfe auszufechten. Brustkorb stark gewölbt, für Lungen mit der nötigen grossen Luftkapazität gebaut. Der Hinterteil des Rumpfes ist im Verhältnisse zum Vorderteil weit schwächer angelegt. Auf seinen kraftrollen Vorderbeinen steht der Bock 1 Meter hoch. fällt aber mit dem Becken ziemlich stark ab. Während die Wildschafe sonst nur eine sehr kurze Schwanzwirbelsäule besitzen, ist sie hier sehr lang: und es trägt der Schwanz ausserdem in gewissen Jahreszeiten eine starke Quaste. Das doppelhaarige Fell passt sich mit seinem fahlen, fast überall einfarbigen Braun den Felsen der Heimat dieser Species in schützender Weise bestens an und besitzt ein grobes, spitzenloses Grannen-, sowie ein feines Wollkleid. Im Sommer dominiert das erstere, im Winter selbstredend das letztere. Der alte Widder erreicht, wie nachgewiesen, ein Gewicht ron 150 Kilogramm. Er tritt anfangs November in die Brunst; doch ist er, mit Ausnahme der Härungszeiten. während des ganzen Jahres zur Begattungfähig und bereit. Das Schaf geht 160 Tage trächtig und setzt zuerst fast ausschliesslich nur ein Lamm, später sehr oft deren zwei. Durch die Nutter kaum trocken geleckt, sind sie schon im Stande zu gehen, erklettern nach 24 Stunden bereits steile Felsen und folgen den Alten nach zwei Tagen mit grosser Be- 
hendigkeit über Stock und Stein. Durch einen einzigen Warnungslaut derselben auf Gefahr aufmerksam gemacht, wissen sie sich auf das Geschickteste zu verbergen, entwickeln sich überhaupt intellektuell und körperlich sehr rasch. Das Naturell des freilebenden Mähnenschafes ist namentlich im jugendlichen Alter ein lebhaftes; ältere Böcke werden hingegen meist sehr streitsüchtig und mürrisch; in die Enge getrieben oder verwundet, können sie selbst gegen den Menschen aggressiv und für den Unbewaffneten gefährlich werdeı. Unter sich befehden sich die Widder mit dem den Schafen eigenen Starrsinn; selbst öfter, als infolge von Verwundung durch das gegnerische Gehörn, endet der eine der Kämpfer sein Leben durch den Sturz über die Felswände, den er gerade dem andern zugedacht hatte.

Der Jäger bewundert die Sicherheit, mit der sein Wild annähernd senkrechte Felsmauern spielend bewältigt, die Ausdauer, mit der es einem für sicher gehaltenen Asyl zueilt, das scharfe Auge und Ohr, sowie den feinen Geruch, durch die es ihn schon auf weite Entfernung entdeckt, endlich die Schlauheit, mit der es sich, wie von einer Versenkung aufgenommen, ganz nahe vor ihm unsichtbar zu machen versteht. Aber ehe er sich von seinem Erstaunen erholt, flieht es, schon in kugelsicherer Entfernung, dahin. Das Mähnenschaf hat auch in dieser Richtung mehr Anschluss an die Steinböcke, als an die bedächtigern Wildschafe, wie sich auch die Jagd auf dasselbe kaum von der auf Steinböcke unterscheidet. Der Erleger unseres im Winter 1896/97 in den südtunesischen Gebirgen erbeuteten stattlichen Museumsexemplars, ein gebildeter Mann und ausgezeichneter Jäger, beschreibt in einer unserer Fachzeitschriften eine seiner bezüglichen 
Jagden im Auszuge wie folgt: „Das Mähnenschaf bewohnt fast alle Gebirgszüge des tunesischen Südens und kommt auf einzelnen Höhenzügen bis tief in die Sahara hinein vor. Seine Jagd ist für den Einzelnen nicht leicht. Ausdauer, scharfes Auge, im richtigen Moment ruhiges Blut und eine sichere Hand sind die unbedingt nötigen Eigenschaften des Jägers auf dieses edle Wild. Ausserdem gehört dazu eine sehr genaue Kenntnis des Gebirges, sowie der Gewohnheiten des Wildes neben ganz bedeutender Gewandtheit im Beschleichen des vorsichtigen, misstrauischen ,Arui'. Diese Eigenschaften sind auch den dort heimischen Beduinen in hohem Masse eigen, die dafür gewöhnlich nur sehr schlechte, meist zwei Meter lange Flinten besitzen, mit denen sie auf höchstens 60 Schritte und nie auf laufendes Wild zu schiessen wagen. Aber ein Beduine, der sich stolz Mähnenschafjäger nennt, verschmäht es, Steinhühner oder Hasen zu jagen, und blickt verächtlich auf denjenigen herab, der sich mit solcher Beute begnügt. Von Beduinen erlegte Mähnenschafe sind indessen für europäische Sammler nicht verwendbar, weil dem Mohamedaner seine Religion gebietet, dem erlegten Wild die Kehle von einem Ohr zum andern durchzusäbeln. Interessant ist es, diese dennoch erfolgreich jagenden Leute laden zu sehen. Das Pulver wird in der hohlen Hand abgemessen, je mehr, desto besser; darauf kommt ein Graspfropfen und auf diesen die Kugel. Und wie sieht diese selbst aus! Nach allen Seiten eckig, ist sie gewöhnlich auch noch zu klein; doch weiss sich der Eingeborne zu helfen. Er bearbeitet das Stück Blei mit seinen Zähnen, bis die dadurch entstandenen Zacken dem Klumpen einen Umfang gegeben, der etwas grösser ist als das Kaliber seines Schiesseisens. Dazu werden noch zwei Posten gefïgt und schliesslich auf alles nochmals 
ein Graspfropfen gesetzt. Im Falle nun Allah so gnädig ist, diese Ladung losgehen zu lassen - dann liegt aber auch das beschossene Stück. Wir Europäer würden ein solches Geschütz mit gewöhnlich gebrochenem, mit Bindfaden wieder gebundenem Schafte, da und dort geplatztem Laufe, um den ein Blechverband angelegt ist, um alles in der Welt nicht losdrücken; denn sehr oft ist es auch noch fürchterlich überladen. - Der Beduine seinerseits sieht mit Stolz und nicht ohne Hohn auf unsere gezogenen Waffen herab. Er weiss, dass seine eigene Jagdkenntnis die wackelige Flinte bestens unterstützt und das einmal erspähte Wild fast immer zur Strecke bringt. Es kommt freilich oft genug vor, dass die halbe Hand des Schützen dabei ebenfalls zur Strecke gelangt; doch es war so Allah's Willen, und sobald die Hand schlecht genug kuriert ist, geht das Schiessen aus dem nämlichen Rohr auf's neue los."

"Mit mehreren tüchtigen Mähnenschaf-Jägern erkletterte ich eben einen Abhang, als der vorderste, welcher den Grat erreicht hatte, plötzlich die Hand erhob, zum Zeichen, dass er Wild erspäht habe. Wir näherten uns ihm lautlos und erblickten nun an der gegenüberliegenden Felswand ein Rudel von fünf Stück. Der Wind war jedoch ungünstig, und wir mussten einen Bogen schlagen, um uns von der entgegengesetzten Seite her zu nähern. Trotz aller Vorsicht sahen wir das Rudel in mächtigen Sätzen verschwinden. Dennoch setzten wir unsern Marsch fort und gelangten so an einen mit Steinblöcken dicht besäten Hang, den unser Wild in solchen Fällen sehr gern aufsuchte. Vorsichtig hinaufschauend, strengten wir unsere Augen aufs äusserste an, aber nichts regte sich. Schon wollte ich missmutig weiter klettern, als einer der Beduinen mich mit den Worten festhielt: ,Es ist Mittag, Herr, die 
Schafe wandern jetzt nicht umher, sondern liegen wiederkäuend im Schatten der Felsblöcke, mit Ausnahme der aufgestellten Wache, die aber so regungslos dasteht, dass sie sehr leicht übersehen wird; lass' uns noch ein Mittel versuchen, das oft hilft.' Mit diesen Worten ergriff er einen grossen Stein und schleuderte ihn den Abhang hinunter, wo er polternd und prasselnd dahinfuhr. Wir alle hatten mit angehaltenem Atem am Boden gelegen, den Erfolg dieses Manövers abwartend; da raunte mir einer der Jäger zu: ,Seht Ihr, Herr, dort stehen sie, das Leittier hat sich bei dem Getöse bewegt. Haltet Euch stille, es ist ein grosses Rudel.' Jetzt sah auch ich dasselbe, freilich nur mit Hülfe des guten Glases, mit dem ich meine scharfen Augen unterstützte, und zählte 17 Stück, welche der Lärm zwar nicht verscheucht, aber doch rege gemacht und die sich nun, nach allen Seiten sichernd, dicht zusammendrängten. Der Wind war uns unterdessen günstig geworden, und da verfolgte Mähnenschafe meist aufwärts flüchten, beschloss ich, das Wild womöglich umstellen und mir zutreiben zu lassen. Zwei Beduinen sandte ich ab, die Tiere zu umgehen, zwei den Ausweg nach links und einen den nach rechts abzusperren. Denjenigen nach oben besetzte ich selbst mit den zwei besten der Jäger. Die fünf Beduinen zogen ab, bei grosser Schnelligkeit dennoch lautlos. Das Rudel hatte sich unterdessen bereits wieder niedergetan. So mochten zwanzig Minuten verstrichen sein, als das Leittier plötzlich den Kopf aufwarf, dadurch das ganze Rudel aufscheuchend, das sich nun sofort gegen meinen Stand hin bewegte. Aber nur im Schritt kam es heran, zeitweise stehen bleibend, nach der Windrichtung hin sichernd. Bald trennte es sich; der grössere Teil desselben zog nach rechts ab, nur ein starker und ein schwä- 
cherer Bock und zwei schwächere Schafe kamen auf uns zu. Ich lag auf den Knieen, den Drilling auf den starken Bock im Anschlag, wollte aber das Wild möglichst nahe herankommen lassen. Da knallt es weit unter mir; im gleichen Augenblicke lasse auch ich meinen Schuss fahren, und der starke Bock bricht im Feuer zusammen. Dem flüchtigen Rudel sende ich auch den zweiten Schuss nach, den das eine Schaf erhält. Die dritte Kugel trifft den schwächeren Bock, tötet aber nicht sofort. Mein Jäger hatte dies bemerkt und streckte ihn bald nachher. Da höre ich auch schon den einen der Beduinen rufen, der ebenfalls einen guten Bock erlegt hatte. - Dies war meine beste Jagd auf Mähnenschafe. Ich wollte und musste die Häute selbigen Tages noch alle salzen, also vorher noch sorgfältig abziehen; denn sie verderben dort in einer einzigen Nacht. Es musste deshalb an Ort und Stelle geschehen, schon weil wir die schweren Tiere nicht so, wie sie dalagen, zum Zelte schaffen konnten. Aus Halfagras wurden Stricke gedreht; die einen beluden sich mit je einem halben Kadaver, die andern mit den Häuten. So langten wir nach langem Marsche todmüde, aber des Erfolges froh bei dem Zelte an. Da dieses Wildpret sehr schmackhaft ist, waren die Beduinen mit dem Tag ebenfalls sehr zufrieden und verabschiedeten sich mit den landesüblichen weitläufigen Danksagungen und Segenswünschen für mich, meine verstorbenen, die zur Zeit vorhandenen und noch zu erwartenden lieben Angehörigen."

„Der Eingeborne bemächtigt sich ausserdem gerne junger Mähnenschafe, die er in verschiedenen Fallen und Schlingen lebend zu fangen versteht, also ohne deshalb die Mutterschafe töten zu müssen, was ihm ohnehin sehr widerstreben würde. Jene werden den fremden Tierhänd- 
lern zugeliefert und gelangen so in die zoologischen Gärten, wo das Mähnenschaf bei Mais, Hafer und Heu gut ausdauert, sich auch schon lange darin fortpflanzt. Auf steinigem, trockenem Boden, der aber auch mit Wasser reichlich versehen sein muss, ist es schon verschiedentlich selbst in Deutschland - in weitläufigen Einfängen mit gutem Erfolg ausgesetzt worden und hat sich hier reichlich vermehrt. Seine Ansiedelung als Jagdwild in Gebirgen, die nicht zu sehr nördlich liegen und ausserdem nicht von Gemsen bewohnt sind, würde auf keine Schwierigkeit stossen, wie die Mähnenschafstände im Karstgebirge beweisen."

Ein erst zehn Monate alter Bock, der im nördlichen Deutschland einem Tierhändler entkommen war, indem er ohne Zaudern in drei Sätzen eine $2^{1 / 2}$ Meter hohe Maner erkletterte und übersprang, trieb sich lange Zeit frei herum, durchschwamm mit Leichtigkeit Flïsse und erwies sich, einst zufällig bei einer Jagd auf Rehe zum Vorschein gekommen und erlegt, als in ausgezeichnetem Zustand und in der Vollkraft des gänzlich wild lebenden Tieres befindlich. - Möglicherweise wird auch diese Wildart einmal unsern st. gallischen Wildpark beleben; doch wollten wir es vorher mit einem andern, kleinern und billigern, unser Klima und die Mängel unserer Parkanlage voraussichtlich leichter überwindenden Wildschaf versuchen. Es ist dies der sardinische Iuflon, bekanntlich das einzige europäische Wildschaf.

\section{Europäischer Muflon. (Ovis Musimon L.)}

Der Muflo (weiblich Mufla) der Sarden, der sich nachweisbar zur Zeit allein noch auf der Insel Sardinien als Wildtier aufhält, scheint früher auch die festländischen 
Gebirgsketten rings um das Mittelmeer bewohnt zu haben. Hierauf scheinen wenigstens die allerdings sehr spärlichen Funde einzelner Zähne und Knochenfragmente aus den Höhlen bei Mentone, dann aus dem Süden Spaniens und von Maghreb in Algerien hinzudeuten. Es ist ja auch nicht anzunehmen, dass diese Tierspecies, so wenig wie andere jetzt ebenfalls nur insuläre Säugetiere, von Anfang an eine insuläre Form gewesen sei. Sehr auffallend ist gleichzeitig, dass der Muflon so sehr lange schon aus den um das frühere wie jetzige Mittelmeer liegenden, weitläufigen und einsamen Gebirgen verschwunden sein muss, und nicht weniger interessant, dass er sich auf Sardinien, dieser zwar grossen und wilden, aber ziemlich stark bevölkerten Insel bis heute verhältnismässig reichlich freilebend zu erhalten vermocht hat. Auf welche Weise derselbe zur insulären Tierform geworden sein kann, verstehen wir leicht, sobald wir uns die frühere Gestaltung des Mittelmeers vergegenwärtigen; standen doch die südöstliche Halbinsel Europas mit Kleinasien, Spanien und Italien mit Nordafrika und die grössern Inseln des Mittelmeers mit dem nächstgelegenen Festland in Verbindung. Europa besass verschiedene Landbrücken, auf denen sich Tierarten von ihm aus weiter ausbreiten, oder aber, nach der Ansicht jener, die überhaupt die Heimat aller grössern Landtiere nach Asien verlegen, von diesem Erdteil aus (abgesehen von dem Tore Europas nördlich vom Kaspi) in den unsrigen einzudringen vermochten. Dass derartige Tierwanderungen, ähnlich den frühern Völkerwanderungen, wirklich stattfinden, wenn die Wege dazu vorhanden sind oder in natürlicher oder künstlicher Weise geöffnet werden, zeigt uns ein grossartiges Beispiel, das unter unsern Augen gegenwärtig vor sich geht. Allerdings bezieht sich diese 
neueste Tierwanderung auf Wassertiere, also auf einen Wasserweg. Durch den Suezkanal zieht nämlich eine stets grösser werdende Zahl von Arten aus dem indischen Ozean in das Mittelmeer hinüber. Je nach der grössern oder geringern Bewegungsfähigkeit dieser Aus-, resp. Einwanderer, je nach der leichter oder schwieriger sich vollziehenden Akklimatisation an die neuen Wasser- und Nahrungsverhältnisse geht diese Übersiedelung in sehr verschiedenen Zeitmassen vor sich. - Genau dasselbe wird es ohne Zweifel bei der Aus- und Einwanderung von Landtieren über alte oder neu entstandene Landbrücken in längst vergangenen Zeiten gewesen sein. - Ist nun der Muflon keine originär insuläre Tierform, und sollte er angesichts des sehr auffallend langen Fehlens nicht nur rings um das Mittelmeer herum, sondern überall ausser auf Sardinien - auch nicht über frühere Landbrücken dorthin gelangt und nach ihrem Verschwinden daselbst zurückgeblieben und so insulär abgesperrt worden sein, so bliebe nur die Annahme übrig, dass der Mensch ihn dorthin gebracht hat. Obgleich letzteres nicht sehr wahrscheinlich ist, so fehlt doch jeder Gegenbeweis. Und wenn wir dann jener schon im grauesten Altertum auf einigen Inseln des griechischen Archipels total wild lebenden Ziegenrudel gedenken, deren jetzige äussere Erscheinung dem Forscher die Entscheidung: ob ursprüngliches Wildoder früheres Haustier, sehr schwer macht, so tritt bezüglich des Muflon diese Ansiedelungsweise aus dem Rahmen des Unmöglichen heraus. Jedenfalls würde die Annahme dieser Möglichkeit als Wirklichkeit eine starke Stütze für jene Forschung bilden, welche mit vorderhand wohl allzu grosser Bestimmtheit den sardischen Muflon als den Stammvater der europäischen Hausschafrassen 
annimmt. Sie würde aber auch die Vermutung bekräftigen, dass der Mensch sich schon sehr lange mit dem Muflon in dieser Richtung beschäftigt, ihn zum Zwecke der Domestikation vom Festlande her nach den italienischen Inseln geholt und dort freigelassen hat. Bekanntlich ist er auf der Insel Korsika erst in neuester Zeit der unablässigen Verfolgung erlegen. Tatsache ist ferner, dass der sardische Muflon sich auch heute noch sehr gerne mit jeder Hausschafrasse und zwar stets fruchtbar vermischt. Er gewöhnt sich auf Sardinien immer noch sehr leicht an den Menschen und an Domestikationsverhältnisse, wird, jung aufgezogen und in stetem Umgange mit Menschen, sehr zahm und gesellt sich so dem Haustiere sehr oft als Haustier zu. Dass übrigens die alten Römer derartige Verpflanzungs- und Domestizierungs-Unternehmungen wirklich ausführten, beweist eine Notiz im siebenten Kapitel des Buches „über den Landbau" von Junius Moderatus Columella von Cadix, einem Zeitgenossen des verrückten Nero, welcher dort sagt, sein Oheim habe Wildschafe aus Afrika nach Italien gebracht, um sie mit der tarentinischen Schafrasse, die unter den Züchtern in hohem Ansehen stand, zu kreuzen. Selbstredend soll damit nicht gesagt werden, jene Wildschafe seien ganz sicher Muflons gewesen, obwohl von nordafrikanischen Wildschafen damals nur das Mähnenschaf und wenn noch ein anderes, dann nur der jetzige sardinische Muflon gelebt hat.

Die Tatsache der unbegrenzt fruchtbaren Vermischung des Muflons mit jeder Hausschafrasse und die durch seine zahlreichen Kreuzungsversuche von Wild- mit Haustieren erzielten Resultate führten den auf diesem Gebiete sehr verdienten Direktor des landwirtschaftlichen Versuchsinstituts in Halle, Prof. Dr. Kïhn zu dem Schlusse, dass 
irgend ein artlicher Unterschied zwischen Muflon und Hausschaf nicht angenommen werden könne, und dies um so weniger, als bei eingehender Untersuchung auch alle vermeintlichen morphologischen und anatomischen Unterschiede zwischen beiden sich als unhaltbar erwiesen haben; der Muflon müsse also der Stammvater des europäischen Hausschafes sein; allerdings sei fremde Blutbeimischung nicht unmöglich. Um hierüber Gewissheit zu erhalten, sagt Kiihn, ist es wünschenswert, nach dieser Richtung auch alle übrigen Wildschafarten auf ihr Verhältnis zum Hausschaf zu prüfen. Es ist ihm nun in Halle selbst gelungen, einen weiblichen persischen Muflon mit einem Rambouilletbock fruchtbar zu kreuzen, sowie die bezüglichen Versuche auch mit dem grossen Wildschaf Nordamerikas erfolgreich fortzusetzen. „Ob aber auch hier, fährt Kïhn fort, wie bei dem europäischen Nuflon, sogar die Bastarde unter sich und selbst bis in die extremste Incestzucht hinein in jedem Blutmischungsgrade fruchtbar bleiben, ist noch nicht erwiesen. "Jedenfalls verdient der Muflon das Interesse, das ihm zur Zeit von Seite der Forscher zugewendet wird, in hohem Masse. Nachdem ich indessen eingangs selbst das Aufstellen von Hypothesen als die Nichtlösung wissenschaftlicher Fragen bezeichnet habe, dürfte es besser sein, keine Reflexionen darüber anzustellen, woher es komme, dass unser Hausschaf nach der Gestalt und Ringelung seines Gehörns und der wackern Ramsnase seine Stammväter viel eher bei den grossen nordasiatischen Wildschafarten zu suchen habe, als bei dem sardischen Muflon mit seinem Sichelgehörn und der steinbockähnlichen Kopfform.

In unserm Wildparke befinden sich zur Zeit 2 Paare des Muflons vom Jahre 1896, die wir einem mir befreun- 
deten sachkundigen Sarden verdanken; von ihm erhielt ich auch die nachfolgenden Originalmitteilungen, geschöpft aus seinen reichen Erfahrungen beim Beobachten des Muflons in Freiheit und Gefangenschaft, seines Lebens und Treibens auf den Klippen des Gennargentu-Gebirges und bei den zahlreichen Jagden auf dieses flüchtige Wild.

Wie bekannt, zählt der Muflon zu den kleinsten Wildschafen, wenn er nicht geradezu das kleinste ist, indem er nur eine Länge von $120-130 \mathrm{~cm}$, , eine Schulterhöhe von $80 \mathrm{~cm}$. und ein Gewicht von 40-50 kg., also das eines schweren Hausschaf-Widders erreicht. Die Gestalt des ausgewachsenen Bockes ist wohlproportioniert; die Gangart lebhaft; Kopfhaltung und das bewegliche Auge, sowie die beständig lauschenden, kurzen, spitzen, kleinen Ohren verraten das intellektuell belebte und geweckte Tier, während sich in der Allgemeinerscheinung körperliche Kraft und Resistenzfähigkeit aussprechen. Das Geblök ist zwar schafartig, doch nicht so eintönig und lang hingezogen wie beim Hausschaf. Das an der Stirne nahe beisammenstehende Gehörn des Widders beschreibt nur eine nahe am Kopf bleibende ${ }^{2} / 3$-Spirale mit leicht auswärts strebenden Spitzenteilen. Das weit weniger gut gestaltete, mehr dem Hausschaf sich nähernde weibliche Tier trägt normaler Weise kein Gehörn, was seine Erscheinung schon an sich wesentlich beeinträchtigt. Auch ist es bedeutend kleiner als das männliche. Nur sehr alte, steril gewordene weibliche Muflons erhalten zur Seltenheit sehr klein bleibende Hornstummeln. So viel mir bekannt, besitzen die Weibchen aller andern Wildschafe stets nur kleine, einander sehr ähnliche und denen der weiblichen Wildziegen sich nähernde Gehörne. Mit dem Gehörnmangel des weiblichen Tieres nähert sich der Muflon wieder dem Hausschaf, bei 
dessen Weibchen jener ebenfalls, Ausnahmen vorbehalten, die Regel bildet. - Die Allgemeinerscheinung des jungen Muflons namentlich bezüglich der Kopfgestalt zeigt so recht deutlich die äusserst nahen verwandtschaftlichen $\mathrm{Be}$ ziehungen zwischen Wildziegen und Wildschafen. Später erst bildet sich bei den einen der Ziegen-, bei den andern der Schaftypus deutlicher aus. Bei unsern Wildparkexemplaren ist mir diese Umwandlung sehr aufgefallen, nicht minder aber auch der Übergang aus dem fast einfärbig fahlbraunen Lammkleid in das lebhaft gefärbte des geschlechtsreifen Tieres und die Umhärung aus dem leichten, hellen Sommer- in den dichten, dunklen Winterpelz. Auch bei dieser Wildtierart scheinen wesentliche Farbennuancen vorzukommen, da schon von unsern 2 Paaren das eine wesentlich heller ist und weit weniger prononcierte Flecken und Streifen zeigt.

Fortpflanzungsfähig wird das Muflonwild zu Ende des zweiten Lebensjahres; doch werden in der Freiheit noch ganz junge Böcke durch die ältern abgeschlagen und gelangen meist nur zu Schafen, die jene bereits belegt haben. - Die Brunstzeit beginnt auf Sardinien gleich nach dem ersten ausgiebigen Regenfall im August und dauert. bis zum Oktober. Anfangs besteht das Rudel noch aus den Mutterschafen und deren ein- und zweijährigen Lämmern. Doch bald sondern sich die Fortptlanzungsfähigen beider Geschlechter vom Rudel ab; die durch die Standböcke befehdeten jungen Widder treiben die Schafe zu eigenen, neuen Rudeln zusammen, die sie nun als ihr alleiniges Eigentum betrachten. Zu dieser Zeit bekriegen sich die Böcke in erbitterten Hornkämpfen. In einem Anlaufe von etwa 20 Metern stürzen sie aufeinander los, so dass es weithin klippert und klappert. Aber obgleich 
solche Kämpfe stundenlang dauern können, gibt es dabei doch keine Tote; es sei denn, dass der eine Widder den andern über eine Felswand hinunterdrängt oder bei geschicktem Ausweichen des letztern den Todessprung selbst macht. Der Sieger umjagt dann eifersüchtig sein erkämpftes, meist aus 20-30 Schafen bestehendes Rudel, das mit grossem Interesse dem Kampfe zugeschaut hat, und sucht es in sichere Entfernung zu bringen.

Nach einer Tragzeit von 5 Monaten sucht das Schaf dichtes Gestrüpp auf, setzt daselbst sein Junges, selten ihrer zwei, und vereinigt sich andern Tages schon mit seinem Säugling gemeinsam mit den andern Schafmüttern wieder zu Rudeln. - Geht das Lamm, was bei feuchtkalter Witterung auch in der Freiheit häufig vorkommt, an dem Genusse nassen Grases zu Grunde, so nimmt die Mutter ihren oder ihre vorjährigen Sprossen wieder zu sich, wahrscheinlich um mit der Milch keine Schwierigkeiten zu bekommen, in analoger Weise wie sich bekanntlich im gleichen Falle sehr oft Haustiere der Jungen anderer Mütter, ja selbst Junger ganz anderer Arten und Gattungen bemächtigen. Stirbt das Junge schon sehr rasch nach der Geburt, so sucht das Mutterschaf den Widder nach 2 Wochen wieder auf und wirft dann oft erst im August oder September nochmals; die Sarden nennen dies die zweite Geburt, ein Vorkommen, welches sich fast jährlich mehrfach konstatieren lässt.

Die Lämmer spielen unter Aufsicht der Mütter sehr anhaltend. Namentlich üben sie sich im Wettrennen nach einem bestimmten Ziele, oft 20-30 mal in einer Tour, um dann wieder behaglich bei ihren Müttern zu ruhen. Jäger und Hirten suchen sich oft der Jungen lebend zu bemächtigen, dieselben durch blinde Schüsse erschreckend 
und gleichzeitig die Alten verscheuchend, während die Lämmer sich lieber auf ihr Versteckenstalent verlassen.

Der schlimmste Feind des Muflons ist ausser dem ihn rücksichtslos verfolgenden Jäger ein aussergewöhnlich hoher Schneefall, durch welchen namentlich die abgesäugten Lämmer schnell dem Nahrungsmangel erliegen oder dem auch dort überall und zu jeder Zeit herumschleichenden Wilderer zur Beute fallen.

Den Tag über und im Sommer bleiben die Muflons ruhig im Walde liegen; erst abends werden sie rege und steigen dann, sich äsend, unter dem Schutze der Nacht empor. Diese ihre natürliche Lebensweise leidet jedoch immer mehr Not durch die beständig um sich greifende Entwaldung des Gebirges. - Zur Winterszeit ziehen sie aus dem Gürtel des Bergwaldes nach den südlich gelegenen offenen Hügeln und wärmern Tälern herab. Sie ändern zu dieser Zeit die Standorte sehr oft, sind den ganzen Tag rege und schlafen wenig. Dann nähren sie sich schlecht und mühsam genug, so dass sie den ganzen Tag mit dem Suchen des Futters: Eicheln, Eichenrinde, alten Körnern, faulen Früchten und steinharten Beeren beschäftigt sind. Im Sommer besteht die Nahrung hauptsächlich aus Erdbeerblättern und Steineichen-Schösslingen.

Auch dieses Wildschaf stellt eine Wache aus und zwar einen alten Widder, der durch einen einzigen wie "fix" tönenden Warnungslaut das scheinbar sich sicher fühlende Rudel zu eiliger Flucht veranlasst. Hiezu genügt auch ein einziger Luftzug, der ihm menschliche Witterung auf unglaublich weite Distanz zuträgt.

Der Muflon meidet in der Freiheit die Gesellschaft von Haustieren jeder Art, nicht am wenigsten diejenige 
von Hausschafherden. Geraten solche in seine Höhen, so verlässt er diese vorübergehend sofort. Selbst in der Fortpflanzungszeit sucht sogar der überall abgeschlagene, sehr hitzige Muflonbock brünstige Hausschafe nicht auf. Da dies auch umgekehrt nicht der Fall ist, so wurde Bastardierung in der Freiheit kaum je beobachtet. Eher kommt eine solche auch auf Sardinien in der Gefangenschaft vor.

Das am besten von Muflons bestandene Gebirge Sardiniens ist das Gennargentu-Gebirg im Osten der Insel, wo die Tiere eine Meereshöhe von 1500-1900 m. bevorzugen. Früher bedeutend zahlreicher als jetzt, da anstatt Rudeln von 100 Stück heute nur noch solche von 30-40 zu sehen sind, ist der Muflon doch immer noch ein häufiges, stets nur zu hitzig verfolgtes Wild. Der Sarde liebt diese Jagd sehr, auch wenn er es nicht auf materiellen Gewinn abgesehen hat. Er kehrt sich leider wenig an Jagdgesetze und Schonzeiten, so dass die Bestände, die ausserdem oft durch schwere Winter, Lawinenfälle, Entwaldungen und epidemische Krankheiten heimgesucht werden, stetig zurückgehen.

In Gefangenschaft gedeiht der Muflon gut auf steinigem, trockenem Felsboden. Er muss sich aber, um gesund $\mathrm{zu}$ bleiben, auf Felsen ausspringen und hetzen können. Das Schlimmste für ihn sind ein nasser, kalter Stand und nasses, kaltes Gras, wie wir dies auch im Wildpark zu bemerken Gelegenheit hatten, da ein junges Stück dadurch einging und die ältern wiederholt an Darmkatarrh erkrankten. Als bestes Futter gilt nach den Erfahrungen der tüchtigsten Tiergärtner ein Gemisch von Gerste, Hafer, Weizen, Buchweizen, geschrotenem Mais und Kleie. Ein Zusatz von Häcksel anstatt Kleie wird 
sehr gern genommen und später sehr ungern entbehrt. Besonders notwendig sind gerbstoffhaltige Pflanzenteile: Eicheln, Rosskastanien, sowie die Gelegenheit, Eichenrinde selbst abzuknappern. Als Rauhfutter dient im Winter Heu, im Sommer neben dem obigen Trockenfutter etwas Gras und Klee.

In Wildgehegen, in denen reinblütige Muflons nicht recht gedeihen wollten. hat man dieselben mit bestem Erfolg mit Zackelschafen gekreuzt und so eine widerstandsfähige Rasse erhalten. Hoffen wir lieber, dass die Muflons unseres Parkes nicht auf dem fatalen Wege irgend einer "Rassebildung“", sondern direkte dadurch stets kräftiger werden, dass wir ihnen nach Möglichkeit jene Lebensbedingungen zu erfüllen suchen, mit denen eine gedeihliche Existenz gleichbedeutend ist!

\section{Nordamerikanisches Bergschaf.}

Dickhornschaf (Ovis montana Desm.).

Als ein Charaktertier der Gebirgsketten Nordamerikas, in seiner imposanten Grösse, mit dem mächtigen Gehörn, nach seinem ganzen anatomischen und morphologischen Bau und der äussern Erscheinung ein typisches Wildschaf, enge an die Riesen unter denselben sich anschliessend und wohl ursprünglich auch ein Asiate, steht der alte Bergschaf-Patriarch einem Steinbilde gleich auf seiner Felswarte inmitten der Klippenwelt der bad lands Dacota's oder Wyomings. Früher weit über die Gebirge namentlich des westlichen Nordamerikas, besonders das Felsengebirge, verbreitet, sind die guten Zeiten für dieses edle Wild längst vorbei. Jene waren es, als es nur durch die Rothaut gejagt wurde, welche sich für ihre geringen Bedürf- 
nisse seines warmen Felles, des Fleisches und auch aller andern Teile zu irgend einem nützlichen Zwecke bemächtigte. Den roten Mann kam dies mit seinen primitiven Waffen sauer genug an; dafür umwob er es in grossem Respekte mit einem ganzen Sagenkranze. In dem Gewirr von Felspyramiden und Türmen, Gräten und Trümmerfeldern, sowie in dem Labyrinth der senkrecht in dieselben eingeschnittenen Klüfte seiner Heimat, 3-4000 Meter über Meer, fühlte sich damals das Bergschaf so wohl geborgen, dass es sich wegen der seltenen Verfolgungen durch den Indianer durchaus nicht veranlasst sah, sein altgewohntes Sicherheitsgefühl mit dem ewigen Gefahrwittern zu vertauschen, geschweige denn deshalb die alte Heimat aufzugeben. Zeigte sich je und je einmal eine wirkliche Gefährde, so spürte es dieselbe meist früh genug und zog sich dann langsam und bedächtig in die innern Teile jener natürlichen Festung von hunderten von Geviertmeilen zurück, um alles weitere geduldig und ruhig abzuwarten. Dann kam aber der weisse Jäger, zuerst ebenfalls ungenügend bewaffnet und ausgerüstet, nachher hingegen mit weittragenden Gewehren, mit Zelten und Hunden versehen und mit jener Jagdwut, Mordgier und Gewinnsucht behaftet, welche die Millionen von Bisons in wenigen Jahrzehnten fast gänzlich ausgerottet haben. Mit den andern grossen Jagdtieren Nordamerikas ist auch der Bestand an Bergschafen äusserst schnell zurückgegangen. „Das Bergschaf," sagt Freund Baillie-Grohman, der sich oft lange Zeit unter den Indianerstämmen aufhielt und mit denselben der Jagd sowohl auf jenes, als auch auf die Schneeziege und den Wapiti oblag, "ist schon sehr selten geworden. Ausser im Nationalpark Wyomings, in dem zwei Rudel von je 60 bis 70 Stück stehen, gibt es wohl nicht 
mehr viele Gegenden mit so grossen Beständen. Namentlich ist den kapitalen Böcken arg nachgestellt worden: denn einerseits macht der hohe Wert eines starken Gehörns seinen Träger zum Ziel der eifrigsten Jäger, anderseits wird ihnen das starre Festhalten an alten Standplätzen sehr rerderblich. So geht denn auch das Bergschaf, dem Bison gleich. der Ausrottung rasch entgegen." - Tm so besser, dass sich unser schönes Museum jener Kraftgestalt aus der nördlichen Welt rechtzeitig rersichert hat, anstatt, wie viele besser dotierte Sammlungen. die Gelegenheit für die Beschaffung dieses und noch manches andern Tieres, das gleich ihm in erster Linie an die Reihe des Terschwindens kommt, zu rersäumen. Wenn es zu spät geworden ist, nützt das Jammern nichts mehr. Schon jetzt wäre auch unser prächtiger Bison konstatiertermassen kaum mehr zum fünfmal höhern Preise erhältlich. trotzdem derselbe erst seit 12 Jahren im Museum steht.

Das Bergschaf ist ein äusserst kräftig, doch nicht plump gebautes Wildschaf. Der rollentwickelte Widder erreicht eine Länge ron $2 \mathrm{~m}$. bei reichlich $1 \mathrm{~m}$. Schulterhöhe: das Schaf je $1^{1 / 2} \mathrm{~m}$. und $80 \mathrm{~cm}$. Der erstere kann bis $175 \mathrm{~kg}$. schwer werden. Er reiht sich sowohl durch die Grössen- und Gerichtsmasse. als in seiner ganzen Erscheinung unmittelbar an das Argalischaf des nördlichen Asiens an. Kopf im obern Teil sehr breit, im ganzen ziemlich kurz und dick. Das sehr kräftig gebaute Gehörn. dessen Torderfläche gegen innen absinkt. beschreibt eine rolle Spirale mit nach aussen getrendeten Spitzenteilen und ist nicht sehr stark quergerunzelt. Bei starken Böcken erreicht es eine Länge ron mehr als $105 \mathrm{~cm}$. und einen Wurzelumfang ron $40 \mathrm{~cm}$. Die Spitzen sind meist abgestossen. zum Teil infolge ron Steinschlag und Stürzen. 
hauptsächlich aber wegen der Kämpfe mit Rivalen. Das Weibchen besitzt nur ein sehr kleines, dem der übrigen weiblichen Wildschafe und dem der Steingeisen sehr ähnliches Gehörn. Auch seine Schädelbildung nähert sich sehr derjenigen der letztern. Der Hals des Widders ist eher kurz, dabei aber äusserst muskelkräftig; gilt es doch, das schwere Gehörn zu bemeistern, was unter vielen Lebensverhältnissen des Bergschafes keine Kleinigkeit ist. Körper gedrungen, mit starker Brust; Extremitäten verhältnismässig schlank gebaut; die Hufe sehr stark: Schwanz nur als kleiner Stummel vorhanden. Die Behaarung ist selbst im Sommer dicht; im Winter bildet sie einen fast undurchdringlichen Doppelpelz; Färbung desselben bei beiden Geschlechtern ziemlich einförmig hellbraun, doch, wie bei allen Verwandten, je nach der Jahreszeit in der Nüance stark wechselnd; am Hinterteil ein weisser Mond; Extremitäten heller als der Rumpf. Die Begattungszeit fällt in den November, und dann geht das Schaf 160 Tage trächtig; die 1-2 Jungen sind wie diejenigen aller Wildschafarten sozusagen ohne weitere Umständlichkeiten mobil und gehen mit dem Mutterschaf, bis sie, durch dasselbe abgetrieben, sich zu eigenen Rudeln zusammentun. Ihre Nahrung ist so schlecht, wie sie die heimischen Höhen von 2-4000 m. liefern können; hauptsächlich besteht sie aus Artemisienstauden und dem kurzen Grase der mattgrünen Bänder auf den Felsbänken und an den steilen Hängen. - Nur die jene Regionen zeitweise durchtobenden blizzards (Schnee- resp. Eisnadelstürme), während deren alles tierische Leben mit dem Tode bedroht ist, zwingen auch das Bergschaf, sich vorübergehend in tiefer gelegene Gegenden zurückzuziehen und in den Bergwäldern Schutz und Nahrung zu suchen. In einzelnen Jahrgängen 
haben solche blizzards arge Lïcken in die Bestände gerissen, die zum Teil nie mehr ausgefüllt wurden.

Die Jagd auf dieses äusserst vorsichtige und flüchtige Wild ist teils durch seine eigentümlichen Lebensgewohnheiten und die Kraft und Ausdauer, mit der es alle Terrainverhältnisse überwindet, teils infolge der Schwierigkeiten, welche jene zerrissene Welt dem nur zweibeinigen, kurzatmigen Jäger entgegenstellt, eine äusserst beschwerliche. Baillie-Grohman, der auf seinen mehrmaligen Jagdreisen nach Amerika an 70 Bergschafe erlegt hat und somit die Jagd samt deren Freuden und Leiden aus eigener Erfahrung wohl kennt, erzählt in einer unserer Fachzeitschriften eine solche, abgekürzt, ebenso interessant wie belehrend: „Das Rerier des nachfolgend beschriebenen Jagdzuges ist eine ächte badland-Landschaft. Die merkwürdigen Bergformationen der bad lands bestehen bekanntlich nicht aus wirklichem Felsgebirg, sondern trotz ihrer Höhe aus Thonerde, die infolge riesenhafter Ausschwemmungen während eines längst rergangenen Zeitalters die eigentümlichsten Gestaltungen angenommen hat. Die bad lands bilden in der Hauptsache eine absolut baumlose, sterile Hochsteppe, ron tiefen. jäh abfallenden Schluchten durchzogen, die nur an einzelnen Stellen überhaupt passierbar sind. Grosse, höchst bizarr geformte Bergkegel, hier zerklüftete Ketten bildend, dort in gigantischen, burgruinenartigen Massen sich auftürmend, erheben sich auf der Hochfläche, über die ich jetzt allein hinreite und die $2900 \mathrm{~m}$. über Meer liegt. Artemisienstauden, niederes Cederngestrüpp und dünn zerstreute Büschel von Buffalogras; alles von der gleichen graugrünen Färbung, sind die einzigen Zeichen vorhandener Vegetation, einer Vegetation, die im Sommer einer Backofenhitze: im Herbst und Winter fast ohne Unter- 
brechung dem immer starken, fast sturmartigen Winde preisgegeben ist. - Dieses ewig gleiche Landschaftsbild würde bald ein recht einförmiges werden, brächten nicht die grotesken, gelb, rot und grau gefärbten Erdbildungen, die auf allen Seiten zum Himmel starren, Abwechslung in dasselbe. Immer höher türmen sich die eigenartigen Berge auf, und bald sehe ich das Ziel meines Rittes vor mir, einen hohen Rücken, dessen terrassenartig aufgebaute hochrote Masse in einer Unmenge ausgezackter Spitzen, Türmchen und Kegel endigt. Die halb kirchturmhohen Stufen dieser Himmelsleiter sind grosse Absätze, die Trittflächen aber oft nur einige Fuss breit. Diese Stiegentritte sind die Lieblingsstandplätze des Bergschafes. Auf dem Bergrücken endlich angelangt, wird abgesattelt, der alte "Boreas" angepflöckt, alles, ausser dem Rucksack mit Proviant, zurückgelassen, und fort geht es zur Spitze eines noch ungefähr $150 \mathrm{~m}$. höhern Kegels, der volle Übersicht über die Grasbänder gestatten wird. Da sehe ich auch schon ein Rudel von etwa 40 Stück, das sich auf einer etwas höher gelegenen Terrasse niedergetan hat. Auf einem zweistündigen Umwege, auf dem ich ausserdem ein kleines Rudel ohne starken Bock weit umgehen musste, um es nicht rege zu machen, erreiche ich erst mein wirkliches Ziel. Das sehr bröcklige Material macht das leise Steigen äusserst beschwerlich, gestattet aber dem Jäger, Klippen zu überwinden, die, wenn aus hartem Fels bestehend, nicht zu erklettern wären. Hände und Kleider kommen dabei freilich schlecht weg; dafür wird der ganze Mensch mit dem rotgelben Staube so gründlich überzogen, dass er dadurch dem Wilde weniger sichtbar bleibt. Endlich auf einer vorspringenden Kanz ${ }_{\text {? }}^{\text {? }}$ auf dem Bauche dahinkriechend, sehe ich herabschauend das grosse Rudel 
auf doppelte Schussweite unter mir; nur der alte Patriarch desselben, auf den allein ich es abgesehen, ist - nicht mehr da! Aber mein altes Jagdpferd erblicke ich in der Grösse eines kleinen Hündchens senkrecht unter mir. Sobald die Sonne, die mir unmittelbar vorher den Platz fast unerträglich gemacht hat, untergegangen, pfeift auch schon der Wind grimmig kalt und gestaltet meine Situation nun wiederum sehr unangenehm. Eben will ich mich aufrichten, um abwärts zu steigen, als plötzlich, kaum 25 Schritte vor mir, ein wahres Riesengehörn auftaucht, dem bald der ganze Patriarch nachfolgt. Da er aber gerade auf die Artemisienstaude herüberäugt, hinter der ich mich befinde, darf ich mich nicht rühren, um die bei Seite gelegte Büchse aufzunehmen. Unterdessen zieht das ganze Rudel unter mir durch; samt ihm, als letztes Stück, verschwindet auch der Stammvater und mit diesem noch das letzte Büchsenlicht. Also heisst es oben bleiben. Ein Felsloch ist bald gefunden. Den eisernen Proviant hervorholen, aus Stauden ein Feuerchen anmachen und doch frieren, wird das Gescheidteste sein! Aber auch die längste Nacht hat ein Ende, und nun geht es der Fährte nach. Am Fuss eines Kamins bemerke ich, dass der Bock „back tracks" genommen hatte, d. h., dass er über Nacht wieder zurück und hinauf gewechselt ist. Der alte Herr musste also doch etwas Verdächtiges gewittert haben, da er sich sonst in der Brunstzeit nicht vom Rudel entfernt. Nach Überwindung neuer, unglaublicher Schwierigkeiten sehe ich aber das Rudel doch wieder unter mir, den Grossvater abseits auf einer Felsenecke seine Morgensiesta haltend. Zwei Minuten später liegt er, trotz sehr starkem Wind, tot auf der nämlichen Stelle. Lange dauert es, bis ich auf weiten Umwegen in der Nähe meiner Beute 
angelangt. Mit dem im Gewehrschaft stets untergebrachten Messband eile ich auf sie zu und schnell ist dasselbe um das Gehörn gelegt. Das Mass ergibt $48 \mathrm{~cm}$., also ein aussergewöhnlich starker Kapitalbock, und so schwer, dass von einem Wenden des Tieres keine Rede ist! Beladen mit dem wohl 25 kil. wiegenden Haupt mache ich mich endlich auf den Rückweg; aber eine ungefügigere Last, um sie über ein so schlechtes Terrain zu schleppen, als diese gibt es wohl kaum. Zuletzt lange ich doch bei meinem alten "Boreas" an, der mich wie immer mit freudigem Wiehern begrüsst. In solcher Einsamkeit, unheimlich in jeder Hinsicht auch für unerschrockene Leute, war es mir, als habe "Boreas" unterdessen jauchzen und singen gelernt. War es doch der Gruss einer mir befreundeten, treuen Kreatur, zu der ich sprechen konnte und die mich verstand. - Das war anno 1882. Seither haben die oben genannten Feinde das Bergschaf dem Verschwinden nahe gebracht." - In allerneuester Zeit kann für dieses Wild auch noch das Goldfieber in Alaska, wo bis jetzt ein Hauptbestand ausgehalten, d. h. der Hunger der über jenes unwirtliche Hochland ziehenden Goldsucher verhängnisvoll werden.

Das in diesem kalten Gebiete wohnende Bergschaf unterscheidet sich zwar von dem des Centrums der Rocky mountains und dieses von dem mexikanischen in einzelnen Gehörndifferenzen und Färbungen der Behaarung. Freunde möglichst vieler Arten spalten daher die eineSpecies geradezu in drei. Begründet ist diese Trennung aber wohl nicht, sondern nur die in drei geographische Varietäten. Ist es doch selbstverständlich, dass eine und dieselbe Säugetierart, von deren Rudeln die einen seit vielen Jahrtausenden die kalte hochnordische Zone, die andern seit ebenso 
langer Zeit tiefere Breitegrade und die dritten noch südlichere bewohnen, allmählich bestimmter ausgebildete Unterschiede aufweisen, die jedoch nicht über den Wert der geographischen Varietät hinausgehen. Die guten Zeiten sind nicht nur für die Dickhorn- oder Bergschafe, sondern auch für die übereifrigen Artenspalter vorbei. Was sich nicht morphologisch und anatomisch deutlich nachweisbar von andern Geschöpfen unterscheidet, wird glücklicherweise jetzt wieder zusammengebracht, und tritt die geographische Varietät je mehr und mehr in ihr wohlbegründetes Recht.

Eine Frage von mehr Bedeutung ist jene, ob das Bergschaf eine originär amerikanische Art sei oder ob es zu der Zeit, da Asien in der Gegend der jetzigen Beringsstrasse mit Amerika verbunden war, herüberwanderte aus den asiatischen Heimstätten der meisten Wildschafarten. Soviel mir bekannt, gilt dieselbe heute für noch unentschieden. Gehen wir aber hinüber von Alaska nach dem Nordosten Asiens, nach Nordost-Sibirien, so finden wir schon dort ein dem Bergschaf sehr ähnliches, ebenso stattliches Wildschaf, das Eisschaf (Ovis borealis Ssewerz.); dasselbe geht bis in die Mongolei hinein und wird auch als die mongolische Varietät des Argalischafes des Altai und der gesamten Asien von Südwest nach Nordost durchziehenden enormen Gebirgsmassive und Ketten bezeichnet.

Bei der reichen Kollektion von Schädeln und Gehörnen beinahe aller bis jetzt bekannter ächter und PseudoWildschafarten der Erde, die ich meist in mehrfachen Exemplaren in meiner Sammlung der Gruppen Capra und Ovis besitze, befinden sich auch Schädel und Gehörn dieser asiatischen Eisschafart, die sehr für die Annahme 
sprechen, dass das amerikanische Bergschaf selbst nur eine geographische Varietät der Ovis Ammon-(Argali)-Formen Asiens ist. Unbedingt hätte ich diesen Gehörnschädel als Ovis montana (Bergschaf) angehörend erklärt, wenn derselbe nicht mit voller Sicherheit durch den Reisenden von Schlagintweit selbst aus Nordostsibirien gebracht worden wäre.

Der Franzose Guillemard fand in Kamtschatka ein weiteres Wildschaf, allerdings nur in kleiner Anzahl, das Schneeschaf (Ovis nivicola Eschscholz), das er für identisch hält mit dem amerikanischen Bergschaf. Nach den mir vorliegenden Schädeln beider Arten steht es jedoch dem Bergschaf entschieden ferner als das Eisschaf und gehört, wie mir scheint, zu den Kaschgaren und nicht zu den Argali's. Wieder andere Forscher halten Ovis nivicola für eine Mittelform zwischen Ovis Argali Pall. und Ovis borealis Ssew., und wenn wir die Altaische Form des Ovis Ammon, die denselben dabei vorgelegen haben wird, neben Ovis nivicola und $\mathrm{O}$. borealis bringen, so ist diese Ansicht wohl begreiflich; nur passt dazu die enorme Entfernung des Altai-Argali von jenen zweien nicht.

Die zwischen der Mongolei und dem Altai lebenden Argaliformen werden wohl ohne Notwendigkeit als eigene Species: Ovis Hodgsoni Ssew., O. Blyth Ssew., Ovis collium Ssew. und Ovis jubata Peters von einander getrennt. Die Unterscheidungsmerkmale laufen auf Subtilitäten hinaus, die eher die Gleichartigkeit dieser Formen im Ganzen und in der Hauptsache, als ihre Verschiedenheit nahe legen dürften. Ausserdem stehen dieselben den speciell als Kaschgare unterschiedenen Wildschafen, welche sich durch ihre auf Kosten des Umfanges um so längern, schnecken- 
artig nach aussen und vorne gewundenen Gehörne kennzeichnen, näher als den Argalis.

Die Kaschgare spalten manche Forscher wiederum in Ovis Polii Ssew., O. Heinsii Ssew., O. Karelini Ssew., O. nigrimontana und O. nivicola Esch. - Stoliczka identifiziert seinerseits das soeben zu den Argali's gezählte O. Blyth mit O. Karelini. Bedenken wir aber schliesslich, wie sehr bei allen Capra- und Ovis-Arten die Gestalt des Gehörnes nach dem Alter, die Dichtigkeit und Farbe der Behaarung je nach der Jahreszeit variieren, so wird uns wenigstens die Unsicherheit in allen diesen Zusammenlegungen und Auseinanderhaltungen klar werden, und diese dauert wohl noch so lange, bis weit vollkommenere Verkehrswege im Innern Asiens zu viel reichhaltigerem Studienmaterial an asiatischen Wildschafen in ganzen Exemplaren anstatt nur in Schädeln und andern einzelnen Teilen verhelfen.

Besser sind wir namentlich durch russische und englische wissenschaftlich forschende und kühn jagende Asienreisende mit der Lebensweise vieler asiatischer Wildschafe bekannt geworden. Es würde indessen zu weit führen, auch diese noch specieller zu erörtern. Nur der Riesengestalt unter allen, dem sogenannten Pamirschaf, mögen in Kürze, nach den Schilderungen Littledale's, noch einige Bemerkungen gewidmet sein.

\section{Pamirschaf (Ovis Polii Ssewerz.).}

Dieses prächtige Tier von der Grösse eines 2-jährigen Rindes, mit ächter Ramsnase und gewaltigem Hörnerschmuck, bewohnt, so viel bis jetzt bekannt, hauptsächlich die sogenannte Pamir-Hochebene, resp. jenes enorme 
Gebirgsknoten-Massiv Centralasiens, in dem der Syr-Darja, der Amu-Darja und der Kaschgar-Darja ihren Ursprung nehmen, und lebt dort im ganzen nach Art der andern Wildschafarten. Bei der grossen Entfernung seiner Wohnstätten von denen des Menschen war es bis jetzt sehr schwierig, ganze Häute, anstatt nur Gehörne und Schädel nach Europa herauszubringen, so dass bloss wenige finanziell bevorzugte Museen sich ihres Besitzes rühmen können. Lebend ist das Pamirschaf trotz sehr hoher bezüglicher Angebote bis jetzt gar nicht nach Europa gelangt, so dass man über sein Gefangenleben noch nichts weiss. Möglicherweise werden hierin die sibirischen Bahnen etwas Wandel schaffen zum Vorteil der Wissenschaft und der Händler, aber sehr zum Nachteil der Tierwelt jener Gebiete. Auch ihr wird dann, wie seinerzeit der amerikanischen durch die Pacificbahnen, die böse Stunde der beginnenden Ausrottung geschlagen haben. Wie der sardinische Muflon in unserm Museum als Vorbild der sämtlichen Muflonarten und das Bergschaf als solches für die Argali's hinsichtlich Gestalt und Hauptfärbung dienen kann, so wird das Pamirschaf bei uns einmal dieselbe Rolle für die Kaschgare übernehmen. Auch seine Hauptfärbung besteht in braun und weiss in allen Abstufungen, und auch ihm kommt wie dem Bergschaf der weisse Spiegel am Hinterteil zu. Das Gehörn ist braungelb. Eine Mähne besitzt es nicht, wohl aber einen sogenannten Nackenkamm und im Winter längere Schulter- und Hinterteil-Behaarung als im Sommer. Welches Wildschaf wohl unser C. Gesner (1550) unter seinem „Weissarss", dem einzigen von ihm überhaupt angeführten, verstanden haben mag, ist um so weniger zu erraten, als gerade der weisse Spiegel bei den Wildschafen sehr stark vertreten ist. Vielleicht hielt er sich dabei doch an eine 
Beschreibung des Pamirschafes, das schon zwei Jahrhunderte vorher durch seinen Entdecker, Marco Polo, bekannt geworden war.

Widder und Schaf sind einander sehr ähnlich. Auch das letztere ist verhältnismässig gross; dagegen sein Gehörn sehr klein, gleich dem aller andern Wildschafe. Ein in nenerer Zeit durch Ssewerzow selbst erlegter, wie er sagt, nicht auffallend grosser Bock, mass von der Schnauze bis zum Schwanze $185 \mathrm{~cm}$., Schulterhöhe $112 \mathrm{~cm}$. , Brustumfang samt Fell $135 \mathrm{~cm}$., Länge der Hörner jederseits $125 \mathrm{~cm}$., Wurzelumfang derselben $38 \mathrm{~cm}$., Abstand beider Spitzen $96 \mathrm{~cm}$. Das lebende Gewicht eines ganz starken Widders kann $300 \mathrm{~kg}$. erreichen. Das stärkste in meiner Sammlung befindliche Gehörn dieser Art misst $158 \mathrm{~cm}$. jederseits, mit $40 \mathrm{~cm}$. Wurzelumfang. - Littledale, der selbst mehrere Exemplare erlegte, hatte Gelegenheit, das stärkste damals bekannte Gehörn. welches vom Maharajah von Kashmir einem Engländer geschenkt worden war, zu messen und fand nicht weniger als $190 \mathrm{~cm}$. Länge, $40,5 \mathrm{~cm}$. Wurzelumfang und $138 \mathrm{~cm}$. Spitzenabstand. Derselbe meldet ferner; er habe auf dem Abchur-Pamir immense Mengen ron Pamirschaf-Gehörnen getroffen. Aus dem sehr hohen Preise, welchen solche Gehörne in Europa haben, lässt sich auf die grossen Exportschwierigkeiten

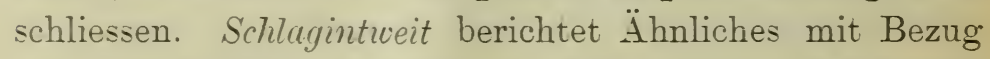
auf den Argali; er habe am Fusse hoher Felswände, über denen Brunstplätze desselben gelegen, grosse Haufen ron Gehörnen liegen sehen. herstammend von lauter im Kampfe mit Rivalen abgestürzten Böcken. Solche Gehörne stellen die Kirgisen auf weiten Strecken längs der einsamen Bergpfade als Wegweiser auf.

Oris Polii ist nach Littledale's Beobachtung kein 
eigentlicher Hochgebirgsbewohner, resp. kein Felsentier, sondern es bevorzuge $3-4000 \mathrm{~m}$. über Meer gelegene Hochsteppen und mit Schwingel, Salzkraut und Wermut bewachsene Abhänge; nur im Falle der Not ziehe es sich in die Felsen zurück und halte an seinen Standplätzen durch das ganze Jahr fest. Die Jagd sei hauptsächlich wegen des ungemein feinen Geruches dieses Wildes äusserst unsicher. Ein einziger Windstoss aus der Richtung des Jägers trage ihm seine Wittrung auf 800 bis 1000 Schritte $\mathrm{zu}$, und wenn dies geschehen, so sei es für lange Zeit nicht wieder zu sehen. Das Pamirschaf könne zwar in jenen Gegenden sogar zu Pferde gejagt werden; indessen sei dort oben selbst ein sehr stark angeschossenes Stück auch mit dem besten Pferde der beklemmenden Luftverhältnisse wegen, unter denen dieses sehr schwer, das Wild hingegen gar nicht leide, nur selten erreichbar. Schliesslich gelang es Littledale doch einmal, zu seiner sauer verdienten Beute zu gelangen; aber das Bergkamel, welches zur Fortschaffung des ganzen für wissenschaftliche Zwecke erlegten Tieres dienen sollte, brachte es unter viel Keuchen in 4 Stunden nur 2,5 Kilometer weit und legte sich dann erschöpft hin. - Angesichts der Ausrüstung zur Pamirschafjagd, wie sie Littledale 1890 für nötig erachtete, wird uns manches erklärlich; für ihn und seine Gemahlin, zum Transport des Gepäckes, Proviantes, Feuerholzes etc. dienten nicht weniger als 40 Pferde. Ausserdem mussten auch noch unterwegs Depots an Holz und Proviant angelegt werden. Das Schlimmste bei einem solchen Unternehmen seien aber die fürchterlichen Schneestürme, die dort zu jeder Jahreszeit ganz plötzlich eintreten und die ganze Expedition mit Mann und Maus vernichten können. Littledale führte in verschiedenen Jahren drei solche Ex- 
peditionen aus, wozu die Zähigkeit und der Reichtum eines Briten gehört, um sie, auch ohne Schneestürme, auszuhalten.

Durch den berühmten russischen Reisenden Przewalski sind in neuerer Zeit noch weitere asiatische Wildschafe bekannt geworden, so Verwandte des Nahoor-Schafes, die aber richtiger als Halbschafe (Pseudoves) bezeichnet werden. - Die Wildschafe des westlichsten Teils von Asien gehören wieder den muflonartigen an, so der prächtige Arkal (Ovis Arkal Brandt) der Turkmenengebiete, dann der Muflon Persiens (Ovis orientalis Gmel.), sowie Ovis anatolica Valenc. in Kleinasien und der cyprische Muflon (Ovis cypria Blas. Ovis Ophion). - Von dort (resp. Syrmien und Sinaihalbinsel) bis Nordafrika gibt es nur Wildziegen oder Steinbockarten. Nordafrika besitzt, wie früher bemerkt, einzig das Mähnenschaf, das jedoch kein typisches Schaf ist. Sardinien endlich beherbergt den nach ihm benannten Muflon. Das europäische Festland entbehrt zur Zeit jedes Wildschafes. Sein Tiefland, die Hügel- und Bergregion, im Sommer auch die Hochalpen beleben nur zahlreiche Hausschafherden verschiedener Rassen, über deren Herkunft und Abstammung auf zoologisch-wissenschaftlichem Wege noch wenig festgestellt werden konnte.

Angesichts dieses Tatbestandes wäre es nach meiner Ansicht nicht gerechtfertigt, das Wenige, was die Sprachwissenschaft da zu bieten vermag, wo die zoologische Forschung vorderhand am Ende ihres Könnens angelangt ist, ohne weiteres von der Hand zu weisen. Ich greife diesbezüglich nur zurück auf die interessante Arbeit von Professor Misteli: "Über indogermanische Säugetiere" (Jahresbericht unserer Gesellschaft von 1866-67). Misteli sagt dort mit Bezug auf das Schaf: "Dass die Wolle 
schon in jenen alten Zeiten geschätzt war - d. h. damals als der indogermanische Sprachstamm noch allein bekannt war - , beweist die allgemeine Übereinstimmung im Namen; das Altindische bietet den Stamm ura = vara nach einer in dieser Sprache ungemein häufigen Zusammenziehung im Schafnamen ura-bhra- und ura-na "Wollträger" und mit der Endung na urnā = varnā "Wolle". Diese Benennung hat sich, wie mir scheint, in den indischen Sprachen bei den Eingebornen für einzelne Wildschafarten lokal erhalten, so z. B. leicht erkennbar in der Bezeichnung des Burrhel-Schafes: Sna, Rna und nahoor, nagar, napo oder snapo $\sigma^{\top}$, namoo $\$$, snamoo. Misteli glaubt weiter, dass auch das lateinische lana (Wolle) = vlana, umgestellt aus valna $=$ altindisch urna $=$ varnā, altindischen Ursprungs sei. Altindisch sei auch avi-, avika-, griechisch ö- = övt-, lateinisch ovi-, gothisch avi-, noch erhalten in avistra "Schafstall" und avethja- "Schafherde", und in Aue = avya "Mutterschaf" (in der Schweiz in manchen Berggegenden noch jetzt hie und da gebräuchlich), englisch ewe von der Wurzel av. Unter den 20 Bedeutungen, welche Westergaard (rad. ling. Sansc.) davon verzeichnet, passt die erste: juvare, tueri, die auch in den Compositis hervortritt, für das Schaf am besten und lässt dasselbe einerseits als Pflegling und Schützling, anderseits als Nutztier des Menschen erscheinen, das ohne diesen kaum seine Existenz fristen könnte.

Möglich wäre es doch, dass die Heimat wenigstens mancher Hausschafrassen in derjenigen der grossen Wildschafe mit der Ramsnase und dem mehr als einmal gewundenen Gehörn, also in Asien gesucht werden müsste, namentlich wenn wir an das allmähliche Überwandern der indogermanischen (arischen) Völkerstämme glauben, 
mit denen dann wohl auch das Hausschaf nach Europa gelangt sein kann. Dass das Schaf schon seit ungemein langer Zeit mit dem Menschen zog, ist als sicher anzunehmen. wie er es auch heute noch in neue Wohngebiete mit sich nimmt, wohin immer er sich wendet. Für den uralten Dienst des Schafes sprechen überdies die früher angedeuteten Funde aus vorgeschichtlichen, unberechenbar weit hinter der Gegenwart zurïckliegenden Zeiten. 


\section{.}






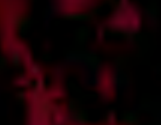

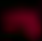
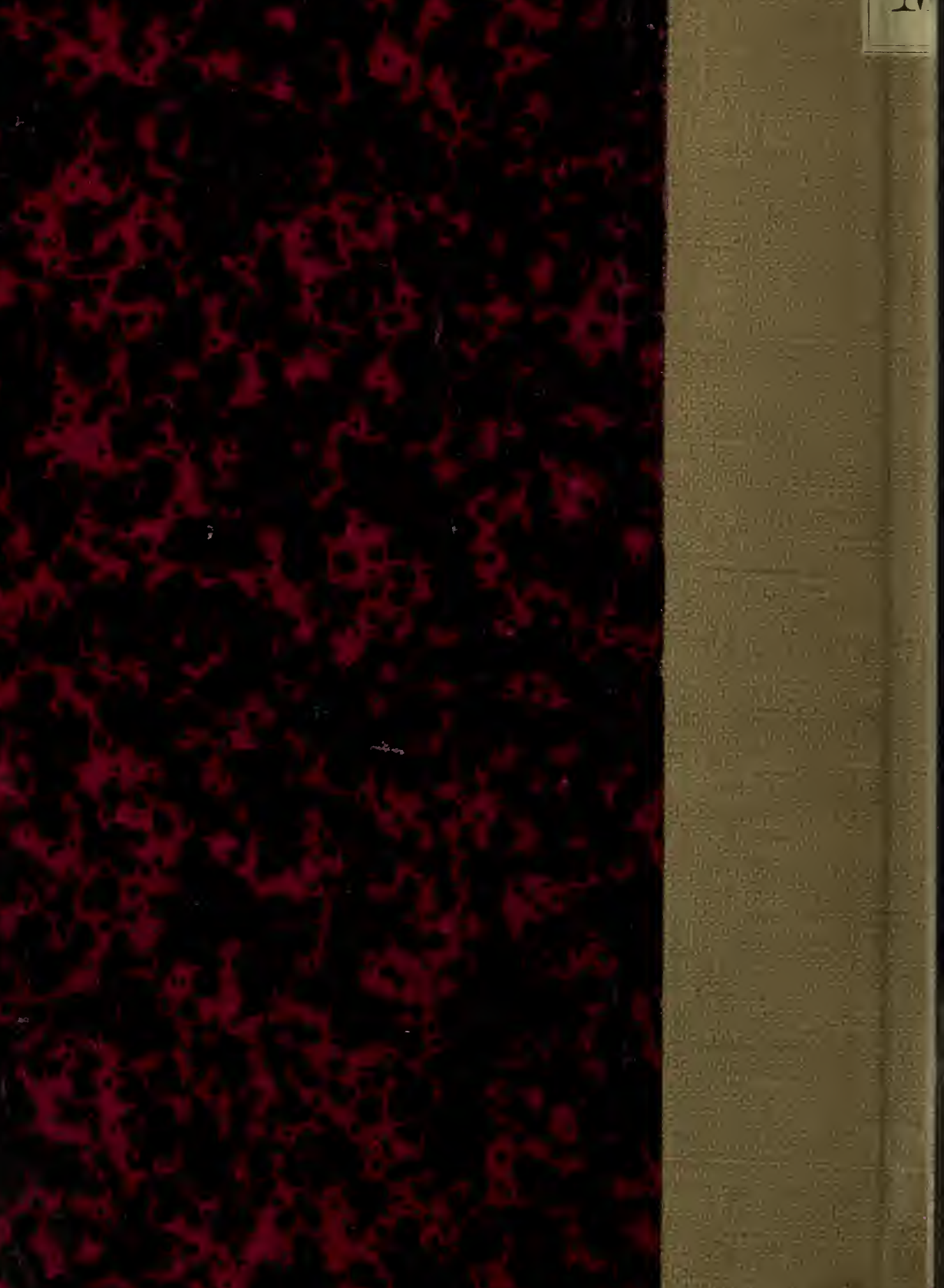